As to the case of evaporated metal films, there is also considerable deviation from the calculated intensity, as we first pointed out some years $\mathrm{ago}^{5}$; these anomalies have now been reproduced by Ornstein and collaborators ${ }^{6}$. Therefore a full explanation cannot be made on some such simple assumption as difference in the shape of crystals or different absorption in different direction. Some other effects such as distortion of the electron cloud and dynamic effects of reflexion have to be taken into account.

K. LARK-HoRovitz.

Department of Physics, H. J. YeARIAN.

Purdue University,

Lafayette, Indiana. August 7.

1 NATURE, 146, 807 (1940).

'Phys. Rev., 48, 631 (1935), particularly p. 634.

${ }^{8}$ See Lark-Horovitz and Ehrhardt, C. H., Phys. Rev., 57, 603 (1940).

4 Phys. Rev., 53, 327 (1938) ; 56, 119 (1939) ; 57, 613 (1940).

${ }^{5}$ Proc. Amer. Phil. Soc., 76, 5 (1936); Phys. Rev., 48, 381 (1935).

${ }^{6}$ Physica, 5, 693 (1938); 7, 685 (1940).

\section{Social Functions of Science}

Is recent discussions on the social functions of science not every contributor has escaped the pitfall of confining the role of science to improving material conditions. I venture to offer the following as a restatement of the more fundamental social function, which is presupposed by the purely material function.

The pursuit of natural science may be regarded as a type or microcosm of all rational life. For, first, scientific work employs reason working upon sensible experience; it requires careful seeking of evidence, and constructive interpretation thereof ; and consequently demands respect for fact, for logic, for insight and for imagination. Second, it exhibits a rational unity of thought and action, in the continual interplay of experiment and theory. Third, it is a social as well as a personal enterprise; as such, it demands respect for the human person and tolerance for diverse opinions, and favours a mental climate which is a balance of appreciation and criticism. It would not be difficult to work out in greater detail the rôle of natural science as a representative type of rational behaviour. All the above characteristics are to be observed also in the running of a business, a farm, or a family, or in any rationally conducted enterprise. The special methods used, and the results, are different in each case, but the spirit defined by these characteristics is common. Moreover, natural science prepares the mind for other rational disciplines, including metaphysics and ethics, which likewise employ both reason and experience; it shares with them the rational spirit, though dealing with a more restricted aspect of experience.

Now natural science, through its influence on daily life, is becoming for many the most easily recognized form of rational behaviour. Further, so long as it remains alive at all, it cannot fail to exhibit rational standards ; false science is easily detected by experiments accessible to all men of science, and moreover, would lead to failures if applied. The most menacing fact of the present time is that the fundamental principles of respect for truth and for the human person (integral elements in the culture bequeathed to us by Christendom) are not everywhere recognized.
In the intellectual chaos of our times, natural science may therefore be an important influence in holding many to rational standards. If men will carry the spirit learned in pursuing natural science into other and more personal activities (without trying to carry over also the special methods of natural science into fields which are much too subtle and too complex for them), we may hope for a more rational world.

The influence of science in this way is no less import. ant than in providing the technique for changing the material conditions of life-indeed it is infinitely more important, since the wise application of science requires direction, which cannot be provided by natural science itself, but only by ethical science and insight. Whether men of science should try to undertake this direction, or whether this social function does not rather stop at propagating the spirit of rational living, is another argument.

\section{Queen's College, Oxford.}

August 12.

\title{
Social Education in the Services
}

Among the three thousand lecturers to the Forces included in the panels of our twenty-three regional committees there are many who offer one aspect or another of science as their subject. The choice of lecturer and topic is, under the agreement made by the Central Advisory Council for Adult Education in H.M. Forces with the Services, dependent upon the expressed wishes of the men and women themselves. It is the function of the Service education officers to ascertain what these interests are. A considerable number of lectures on scientific subjects and classes in either pure or applied science have been provided. The resources of the universities, local education authorities and voluntary bodies have been placed fully at the disposal of the Services for this purpose.

The article in NATuRE of August 16, p. 173, appears to overlook the existence of all this co-operative activity on the part of the Services and the civilian educational bodies. It might perhaps surprise the writer to learn that on the estimate of the Director of Army Education, a million men and women in the Army attended lectures in the course of a recent month. The demand for educational facilities of all sorts has been maintained right through the summer and may well develop still further during the coming autumn and winter. At a recent conference of regional committee secretaries it was agreed that scientific subjects ought to take a larger place in the programme; but it was pointed out that those who offer them do not always present either attractive titles or an exposition which makes scientific facts and theories relevant to the interests and the thought of ordinary men and women. From this point of view the suggestions made in the article are particularly valuable and I hope that they will be very widely followed by lecturers, actual or potential, to the Forces. in H.M. Forces,

Rewley House, Wellington Square, Oxford.

Aug. 23. 